\title{
Pregnancy in the rudimentary horn - the culprit behind a catastrophical outcome
}

\author{
Mayuri Ahuja, Ruchi Srivastava, Shehla Jamal \\ Correspondence: Dr Mayuri Ahuja, Flat no 203, old staff quarters, Sharda campus, \\ knowledge park 3. Greater Noida, India; Email - soniaahuji@rediffmail.com \\ Distributed under Attribution - NonCommercial - Share Alike 4.0 International (CC BY-NC-SA 4.0)
}

\begin{abstract}
Pregnancy in a non-communicating rudimentary horn is of very rare occurrence. Delayed and initial misdiagnosis can result in catastrophic outcome both for the fetus as well as the mother. We present a case of 24 years old $\mathrm{G}_{3} \mathrm{P}_{2} \mathrm{~L}_{1}$ with ruptured pregnancy in a rudimentary horn which due to misdiagnosis resulted in maternal near miss.
\end{abstract}

Keywords: Rudimentary horn, pregnancy, ultrasound.

Pregnancy in the rudimentary horn of unicornuate uterus occurs in 1: 76000 to 1:150000 of all pregnancies. ${ }^{1}$ The rudimentary horn is non-communicating in $83 \%$ of cases. ${ }^{2}$ Ultrasound detection rate is of only $26 \%$ and the rate of detection decreases as the gestational age advances. $^{3}$ The initial misdiagnosis can result in significant morbidity and mortality. With the advancement of ultrasound technology, the role of paracentesis in cases of distended abdomen cannot be bypassed. The detection of hemoperitoneum on paracentesis provided an aid to the final diagnosis which eventually prevented maternal mortality.

\section{Case Report}

A 24-year-old $\mathrm{G}_{3} \mathrm{P}_{2} \mathrm{~L}_{1}$ presented to the hospital with four month amenorrhea, pain lower abdomen on and off for the past 2 days, breathlessness and dizziness since one day. Her previous child birth was a still born male at 7 months of gestation. Her other issue was also a preterm birth at 8 months of gestation five years back. Pregnancy was confirmed by positive home urinary pregnancy test. No scans were done during this pregnancy.

At the time of presentation, she was conscious and oriented but had severe pallor. Pulse was $140 / \mathrm{min}$, blood pressure was $80 / 40 \mathrm{~mm} \mathrm{Hg}$ and abdomen was distended. Uterus was diverted to the right side, fundal height and exact size could not be estimated on per vaginal examination. Her investigations revealed $\mathrm{Hb}: 5 \mathrm{~g} / \mathrm{dl}$, TLC: $23,000 /$ cumm, platelet count: 50 thousand and viral markers were negative. Her USG revealed gross ascites and intrauterine fetal demise at 13 weeks of gestation. With a presumptive diagnosis of sepsis with ascites with IUD, parentral fluids, nor-adrenaline drip, two units packed red blood cells arranged and transfused. Broad spectrum antibiotic coverage was also done. After 5 hours of initial resuscitation the patient condition further deteriorate. Patient was intubated. Noradrenaline drip was accelerated from $2.5 \mathrm{ml} / \mathrm{hr}$ to $10 \mathrm{ml} / \mathrm{hr}$. The increasing abdominal distension prompted the performance of

Received: $25^{\text {th }}$ May 2019. Accepted: $13^{\text {th }}$ June 2019.

Ahuja M, Srivastava R, Jamal S. Pregnancy in the rudimentary horn - the culprit behind a catastrophical outcome. The New Indian Journal of OBGYN. 2019; 6(1): 71-3. 
paracentesis which revealed hemoperitoneum. Rescanning was done which revealed bicornuate uterus with ectopic gestation in left adnexa. Decision for emergency laparotomy was taken. Laparotomy revealed hemoperitoneum of around 2 liters, fetus was found lying in adnexa with placenta attached to the ruptured left rudimentary horn. The rudimentary horn was connected to the unicornuate uterus by a fibrous band. The other half of unicornuate uterus with tube and ovary were found to be normal. Left ruptured rudimentary horn with placenta in situ was excised. The left tube and ovary were left behind. Patient was given altogether 4 units of packed red blood cell, 6 units of fresh frozen plasma, and 4 units of platelets. Peritoneal lavage was done and peritoneal drain was inserted. Abdomen was closed and patient was shifted to ICU for ventilatory support. The next day the ventilator was weaned off and inotropes were tapered. Patients drain and catheter were removed on postoperative day 2. Patient showed good recovery postoperatively and discharged on eighth postoperative day. The histopathology report of the excised horn suggested placenta accrete syndrome.

\section{Discussion}

Pregnancy in the rudimentary horn is of rare occurrences. It is the most life threatening situation due to torrential haemorrhage after rupture which can result in significant maternal morbidity and mortality. One of the main reasons for its low detection is the low clinical index of suspicion due to nonspecific clinical symptoms and signs and low ultrasonographic sensitivity. The history of failed attempt of termination of pregnancy after misoprostol should not be neglected as this could be due to pregnancy in the rudimentary horn. ${ }^{4}$ Per vaginal findings are of minimal aid as they are highly nonspecific and only documented finding in such cases was a deviated uterus which was also seen in our case. Majority of the time the diagnosis is intraoperative. The detection rate and sensitivity of ultrasound decreases with the advancing gestational age as once the pregnancy is diagnosed as intrauterine the other horn is not normally searched but antenatal diagnosis has previously been documented. ${ }^{5}$ Tariif et al have suggested three criteria for its diagnosis pseudo-pattern of endometrium, absent between cervix and gestational sac, presence of myometrium around the gestational sac. ${ }^{6}$ Our case presented as gross ascites with shock with USG diagnosis of intrauterine demise. The initial finding of elevated TLC and IUFD with ascites led us to the work up on the lines of septicemia. Her deteriorating condition and no apparent cause for ascites prompted us to perform paracentesis. Paracentesis for the sole aim of making a diagnosis of ruptured ectopic is not recommended but in our case we suspected ruptured ectopic only after bloody tap on paracentesis. With the near universal availability of USG, need for paracentesis is obviated but its importance cannot be under mended especially in rare cases such as rudimentary horn of unicornuate uterus.

The differential diagnosis may include: ectopic pregnancy, abdominal pregnancy and pregnancy in one of the horns of the bicornuate uterus. Even on laparotomy the diagnosis is difficult due to hypertrophy of the rudimentary horn. In tubal ectopic the round ligament is placed downwards where as in the rudimentary horn they are placed laterally. ${ }^{7}$ In case of bicornuate uterus the uterosacrals are attached separately to each of the horns. ${ }^{8}$ In our case, both the uterosacrals were attached to the unicornuate uterus hence diagnosis of unicornuate uterus with pregnancy in rudimentary horn was made. Pregnancy in rudimentary horn can have the following outcomes ranging from preterm labor, fetal growth restriction. The timing of rupture depends upon the musculature of the rudimentary horn. Jin Woo have documented a live birth at 34 weeks in a non- communicating rudimentary horn. ${ }^{9}$ Even if these pregnancies are diagnosed before rupture on ultrasound the prognosis is guarded and decision to continue such pregnancies requires a close follow up. The recommended management is excision of the rudimentary horn with the ipsilateral tube either laproscopically or via laparotomy and this depends upon the haemodynamic status of the patient. Salpingectomy is recommended to avoid future ectopic pregnancies. ${ }^{10}$ Due to posterior and low placement of the left tube it was difficult to remove in our case. Cases with excised rudimentary horn with regard to their future fertility are yet to be followed and studied.

\section{Conclusion}

The non specific symptoms and signs, viable clinical presentation, low sensitivity of ultrasonography for the diagnosis, difficult intraoperative diagnosis makes this entity a challenging situation both for the radiologist as 
well as the obstetrician. Pregnancy in the rudimentary horn is a culprit behind a catastrophical outcome hence even though of very rare occurrence this entity should be kept in mind when dealing with pregnancy with a distended abdomen.

Acknowledgement: I am thankful to Dr S S Gulati for his contribution towards this case report.

\section{Conflict of interest: None. Disclaimer: Nil.}

\section{References}

1.Ural SH, Artal R. Third trimester rudimentary horn in pregnancy - A case report. J Reprod Med. 1988; 37: 919-21.

2.Jayasinghe Y, Rane R, Stalewski H, Grover S. The presentation and early diagnosis of the rudimentary uterine horn. Obstet Gynecol. 2005; 105; 1456-67.

3.Jain R, Gami N, Puri M, Trivedi S. A rare case of intact rudimentary horn pregnancy presenting as hemoperitoneum . J Hum Reprod Sci. 2010; 3: 113-5.

4.Kanagal D, Hanumanalu. Ruptured Rudimentary horn pregnancy at 25 weeks with previous vaginal delivery - A case Report. Case Reports in Obstetrics and Gynecology. 2012; Article ID 985076, 4 pages
5.Fedele L, Dorta P, Vercellini M, Brioschi D, Candidani GB. Ultrasound in the diagnosis of subclass of unicornuate uterus. Obstetrics and Gynecology. 1988; 71(2):274-7.

6. Tariff N, Rojansky, Sela H, Gomari J, Nadjari M. Rudimentary horn pregnancy : first trimester prerupture sonographic diagnosis and confirmation by magnetic resonance imaging. Journal of Ultrasound in Medicine. 2005; 24(2): 219-23.

7.Myerscough PR. Munroker Operative Obstetrics. 10th edition. London: Baillière Tindall; 1982. pp 687-9.

8.Maria L, Maria T, Francisco S. Variations in clinical presentation of unicornuate uterus with non -communicating rudimentary horn (Class B of American Fertility Society Classification). Taiwanese Journal of Obstetrics and Gynecology. 2018; 57(1) :110-4.

9.Shin JW, Kim HJ. Case of live birth in a noncommunicating rudimentary horn of pregnancy. J Obstet Gynecol Res. 2005; 31: 329-31.

10.Lawhon BP, Wax JR, Dufor RT. Rudimentary uterine horn pregnancy diagnosed with MRI imaging. Obstet and Gynecol.1988; 91(5): 869.

\section{Mayuri Ahuja ${ }^{1}$, Ruchi Srivastava ${ }^{2}$, Shehla Jamal ${ }^{3}$ \\ ${ }^{1}$ Senior Resident; ${ }^{2}$ Professor; ${ }^{3}$ Assistant Professor, Department of Obstetrics and Gynecology, School of Medical sciences and Research, Greater Noida, India.}

